\title{
Effect of concomitant administration of oxycontin and amitriptyline on patients with severe cancer pain and depression
}

\author{
Chen $\mathrm{Di}^{1}$, Ding $\mathrm{Xu}^{2}$ \\ ${ }^{1}$ Department of Pharmacy and Medical Examination, Nantong Health College of Jiangsu Province, No. 288 Zhengxingdong \\ Road, Nantong, Jiangsu Province 226010, ${ }^{2}$ Department of Pharmacy and Chinese Medicine, Jiangsu College of Nursing, No. 9 \\ Avenue of Science and Technology, Huaian, Jiangsu Province 223001, China
}

*For correspondence: Email: pm1186@163.com

Sent for review: 1 November 2018

Revised accepted: 29 December 2018

\begin{abstract}
Purpose: To study the effects of oxycontin combined with amitriptyline on patients with severe cancer pain and depression.

Methods: Patients with severe cancer pain and depression $(n=46)$ were randomly divided into two groups. The study group was given oxycontin combined with amitriptyline, while the control group received only oxycontin, each over a period of 4 weeks. Analgesic effect and depression relief were evaluated using FPS-R (Faces Pain Scale-Revised) and HAMD17 (Hamilton Depression Rating Scale 17-Item). In addition, the dose of medication and adverse drug reactions were monitored.

Results: Pain in patients in the two groups were significantly relieved after treatment $(p<0.01)$. Symptoms in the study group were significantly improved, when compared with the situation before treatment, while HAMD17 scores significantly decreased $(p<0.01)$. The mean dosage of oxycontin in the study group in the fourth week after treatment was significantly lower than that of the control group $(p<0.01)$. There were no obvious differences in adverse reactions between patients in the two groups. Conclusion: Oxycontin combined with amitriptyline effectively controls severe cancer pain, and ameliorates depression and improves the quality of life of patients with advanced cancer.
\end{abstract}

Keywords: Cancer pain, Depression, Oxycodone, Amitriptyline, FPS-R, HAMD17 scores

\begin{abstract}
This is an Open Access article that uses a funding model which does not charge readers or their institutions for access and distributed under the terms of the Creative Commons Attribution License (http://creativecommons.org/licenses/by/4.0) and the Budapest Open Access Initiative (http://www.budapestopenaccessinitiative.org/read), which permit unrestricted use, distribution, and reproduction in any medium, provided the original work is properly credited.

Tropical Journal of Pharmaceutical Research is indexed by Science Citation Index (SciSearch), Scopus, International Pharmaceutical Abstract, Chemical Abstracts, Embase, Index Copernicus, EBSCO, African Index Medicus, JournalSeek, Journal Citation Reports/Science Edition, Directory of Open Access Journals (DOAJ), African Journal Online, Bioline International, Open-J-Gate and Pharmacy Abstracts
\end{abstract}

\section{INTRODUCTION}

Cancer pain is caused by tumor infiltration and metastasis, and also by anti-cancer treatments. The pain is mostly chronic and unremitting. Cancer pain is one of the most distressing symptoms related to cancer [1]. Uncontrolled pain is a major public health problem. People with cancer-related pain require proper pain evaluation and treatment by well-trained health care professionals [2].

Young people with cancer suffer multiple symptoms which exert adverse effects on their quality of life [3]. Children with cancer often report pain (up to $89 \%$ in the advanced stage of disease) and over $70 \%$ of the children sometimes report severe pain [4]. Poor pain 
control and side effects of painkillers may adversely affect body function, social activities and quality of life.

Although there are differences in the pathogenesis of cancer pain, treatment generally involves various pharmacology- and nonpharmacology-based therapies [5]. Pain control may sometimes be ineffective, resulting in sustained pain. However, a lot can be learnt about pain management from Cancer Pain Control Guides, including guides issued by WHO, National Comprehensive Cancer Network and European Palliative Care Association. There is need to get information about cancer-related pain in order to improve pain management and palliative care by pain specialist in the early diagnosis of disease [6]. There are also documents showing that patient-based pain education plan results in some improvements in patients.

However, the intervening measures are heterogeneous, and improvements were reported in less than one-third of the studies, and in less than $20 \%$ of patients [7]. About 60 to 80 $\%$ of advanced cancer patients have cancer pain, especially severe cancer pain which influences their psychological and physiological states, easily causing depression. Over $60 \%$ of advanced cancer patients have symptoms of depression [8]. These symptoms negatively influence overall life quality and patients' compliance with treatment, aggravate cancer pain to a certain degree, and even worsen the death rate of patients $[9,10]$.

The present study adopted a combination treatment using oxycontin and the antidepression drug amitriptyline to treat patients with severe cancer pain and depression in our hospital to see the effect of the combination on cancer pain and depression. Analgesic effects, depression relief and adverse reactions were monitored so as to effectively control cancer pain and improve treatment methods for depression.

\section{EXPERIMENTAL}

\section{General clinical profile of subjects}

Cases with severe cancer pain and depression $(n=46)$ admitted in Jiangsu College of Nursing from March 2017 to September 2018, were used as subjects in this study. They consisted of 27 males and 17 females. There were 13 subjects with lung cancer, 6 with gastric cancer, 8 with liver cancer, 4 with colon cancer, 5 pancreatic cancer cases, and 10 cases of cervical cancer. The 46 patients were randomly divided into two groups: control and study groups. There were 23 cases in the control group, with mean age of $50.84 \pm 10.62$ years and average disease course of $13.73 \pm 7.28$ months. The study group had 23 subjects with mean age of $51.33 \pm 9.97$ and average disease course of $12.88 \pm 8.15$ months. There were no statistical differences with respect to sex, age and disease course of patients between the two groups $(p>0.05)$.

This research was approved by the Ethical Committee of Department of Pharmacy and Chinese Medicine, Jiangsu College of Nursing, No. 9 Avenue of Science and Technology, Huaian, Jiangsu Province, 223001 (approval no. 20189447), and performed according to the guidelines of Declaration of Helsinki promulgated in 1964 as amended in 1996 [11].

\section{Inclusion criteria}

Patients diagnosed with malignant tumor by histopathology, patients with tumor TNM at stages II to IV; patients with pain closely related to malignant cancer (FPS-R $\geq 7$ points, and those who met the depression diagnosis criteria of the Chinese Classification and Diagnosis of Mental Diseases [12] and HAMD17 score $\geq 7$ points, were included in the study. In addition, patients with survival time over 1 month were included as study subjects.

\section{Exclusion criteria}

The excluded patients were those with a history of nervous system and mental disease, those who took anti-depression drugs two weeks before the study, patients with multiple organ failure and signs of unstable life, and patients for whom the treatments drugs were contraindicated.

\section{Treatments}

The study group was given oxycontin combined with amitriptyline, while the control group was given oxycontin alone. Patients without opioid usage history were given $10 \mathrm{mg}$ oxycontin every $12 \mathrm{~h}$, while those with opioid usage history were given 10 to $20 \%$ increases in oxycontin dosage depending on the opioid overall dosage, once every $12 \mathrm{~h}$. Drug modification and measure conversions followed the Guidelines for the diagnosis and treatment of cancer pain [13]. Amitriptyline was given at a dose of $12.5 \mathrm{mg}$ once by oral administration before sleep. The dose was gradually increased to $25 \mathrm{mg}$ at a time, depending on the symptoms and signs manifested by the patient. Patients in both groups were observed for 4 weeks, during which 
evaluations of pain and depression were conducted. Adverse effects as a function of drug dose were observed and recorded.

\section{Evaluation of cancer pain}

The evaluation of cancer pain grading was conducted according to FPS-R guideline. In this system, grades 1 to 3 are classified as mild pain, grades 4 - 6 are moderate pain, while grades 7 10 refer to severe pain. Evaluation was performed on weeks 1, 2 and 4 before and after treatment. Evaluation criteria of cancer pain [14] were: complete disappearance of pain (complete relief, CR); obvious improvement and nondisturbance of sleep (partial relief, PR); slight relief of pain, with pain still present, disturbing sleep and life (mild relief, MR), and no relief of pain (NR). The degree of relief was estimated as in Eq 1 where Rcp is the relief of cancer pain and $\mathrm{T}$ is total no. of cases.

$\operatorname{Rcp}(\%)=[(C R+P R) / T] \times 100$

\section{Evaluation of state of depression}

Depression was evaluated using HAMD 17 scoring scale. Combination examination was conducted using communication and observation method by two trained clinical physicians who performed separate and independent assessments viz: mild depression: 7 points < HAMD rate $\leq 17$ points; moderate depression: 17 points < HAMD rate $\leq 24$ points, and severe depression: HAMD rate $>24$ points. Evaluation was conducted once using the same method on weeks 2 and 4 before and after treatment.

\section{Statistical analysis}

Measurement data are presented as mean \pm standard deviation (SD). Measurement data were compared using equation analysis and $t$-test. Enumeration data were compared using chi square $\left(\mathrm{X}^{2}\right)$ test. Statistical analysis was done with SPSS version 19.0 software. Values of $p<$ 0.05 were taken as indicative of statistical significance.

\section{RESULTS}

\section{Effects of treatment on cancer pain}

Compared with the situation before treatment, cancer pain in most patients in two groups were effectively controlled. There were significant decreases in FPS-R scores after treatment, relative to scores before treatment, and the scores were controlled within 3 points $(F=71.52$, $p<0.001$ ). After 4 weeks of treatment, cancer pain in 7 patients was slightly relieved in the two groups. In the study group, cancer pain relief was $86.96 \%$, while that of the control group was $60.87 \%\left(x^{2}=4.06, p=0.044\right)$. These results are shown in Tables 1 and 2.

\section{Improvement in depression}

As shown in Table 3, after 2 and 4 weeks of treatment in the control group, although HAMD17 score decreased, when compared with value before treatment $(p<0.05)$, there were no improvements in depression in the patients. The mean HAMD17 score was over 17 points. However, in the study group, there was obvious improvement in the depression of patients, relative to the pre-treatment situation and the control group $(p<0.01)$.

\section{Dosage of medication (oxycontin)}

As shown in Table 4, there were no statistically significance in initial oxycontin dosage between the two groups $(p>0.05)$. In the control group, mean medication dosage increased during treatment process,

Table 1: FPS-R scores of cancer pain (mean \pm SD, points)

\begin{tabular}{lcccccc}
\hline Group & $\begin{array}{c}\text { Before } \\
\text { treatment }\end{array}$ & $\begin{array}{c}\text { 1 week after } \\
\text { treatment }\end{array}$ & $\begin{array}{c}\text { 2 weeks after } \\
\text { treatment }\end{array}$ & $\begin{array}{c}\text { 4 weeks after } \\
\text { treatment }\end{array}$ & F & P-value \\
\hline Control & $8.01 \pm 1.75$ & $3.31 \pm 1.36^{\mathrm{a}}$ & $3.14 \pm 1.17^{\mathrm{a}}$ & $2.89 \pm 1.21^{\mathrm{a}}$ & 71.52 & $<0.001$ \\
Study $(\mathrm{n}=23)$ & $8.06 \pm 1.54$ & $3.26 \pm 1.31^{\mathrm{a}}$ & $2.77 \pm 1.52^{\mathrm{a}}$ & $2.53 \pm 1.41^{\mathrm{a}}$ & 75.36 & $<0.001$ \\
\hline${ }^{\mathrm{a} P}<0.01$, compared & with value before treatment & & & &
\end{tabular}

${ }^{\mathrm{a}} P<0.01$, compared with value before treatment

Table 2: Effect of treatment on cancer pain $(\mathrm{N})$

\begin{tabular}{lccccccc}
\hline Group & $\begin{array}{c}\text { Complete } \\
\text { relief }\end{array}$ & $\begin{array}{c}\text { Partial } \\
\text { relief }\end{array}$ & $\begin{array}{c}\text { Mild } \\
\text { relief }\end{array}$ & $\begin{array}{c}\text { No } \\
\text { relief }\end{array}$ & Relief (\%) & $\mathbf{X}^{2}$ & $\boldsymbol{P}_{\text {-value }}$ \\
\hline Control $(\mathrm{n}=23)$ & 3 & 11 & 9 & 0 & $60.87^{*}$ & 4.06 & 0.044 \\
Study $(\mathrm{n}=23)$ & 2 & 18 & 3 & 0 & $86.96^{\mathrm{a}}$ & & \\
\hline${ }^{\mathrm{a}} P<0.01$, compared with the control group & & & & &
\end{tabular}

${ }^{\mathrm{a}} P<0.01$, compared with the control group 
with significant increases in mean medication in four weeks, and mean dosage of medication in the fourth week of treatment, when compared with initial dosage $(p<0.01)$. Daily oxycontin usage dosage during the treatment process in the study group was significantly higher than the initial dosage, but lower than the dosage in the control group $(p<0.05)$.

\section{Adverse reactions to drugs}

As shown in Table 5, the adverse reactions seen included constipation, decreased appetite, nausea, vomiting, vertigo, somnolence and urine retention. Some of these adverse reactions were relieved after symptomatic treatment. There was no severe adverse reaction such as respiratory arrest in the two groups.

\section{DISCUSSION}

Cancer pain, especially severe cancer pain, severely affects the quality of life of advanced cancer patients. The focus of the treatment for advanced cancer patients is effective relief of cancer pain. Currently, morphine, as first-line drug for treatment for moderate and severe cancer pain, is unable to remove up to $30 \%$ of cancer pain. Oxycodone can be used for treatment of cancer pain that morphine cannot relieve [15]. Oxycodone is a partial synthetic product of opioid drugs extracted from the alkaloid thebaine, which disturbs algesia by combining with opioid receptor and simulating endogenous opioid peptide, thus playing analgesia effect. Oral preparation of oxycontin is a slow-release drug which can last 8 to $12 \mathrm{~h}$ and effectively control chronic cancer pain [16].

In the present study, the use of oxycontin to treat patients with severe cancer pain resulted in significant decrease in FPS-R score. Although 7 patients had mild relief in the two groups, there was cancer pain relief, relative to the situation before treatment. It is worth noting that there were individual differences in responses to the analgesic effects of oxycontin. Medication dosage totally differed, although FPS-R score was not changed. Therefore, the dosage of oxycontin for treating cancer pain should be promptly adjusted according to the conditions of individual patients.

Apart from cancer pain, depression is also an important factor that influences life quality of advanced cancer patients [8]. In the past, cancer pain accompanied by depression was managed through psychological intervention, but the effect was not always satisfactory. Amitriptyline is one of the popular tricyclic antidepressants at present. It acts by interfering with the reuptake of methylepinephrine and 5-hydroxytryptamine at nerve endings, thereby enhancing neurotransmitter concentration at the synaptic cleft and exerting anti-depressive effect. In this study, analgesia treatment was done with oxycontin alone. The HAMD17 score of patients decreased after treatment, but there was no basic relief from depression. The HAMD17 score after 2 and 4 weeks of treatment was over 17 points. There were significant decreases in HAMD17 score after 2 and 4 weeks of amitriptyline treatment.

Table 3: HAMD17 scoring during treatment (mean \pm SD, points)

\begin{tabular}{lccccc}
\hline Group & Before treatment & $\begin{array}{c}\text { 2 weeks after } \\
\text { treatment }\end{array}$ & $\begin{array}{c}\text { 4 weeks after } \\
\text { treatment }\end{array}$ & F & P-value \\
\hline Control $(\mathrm{n}=23)$ & $19.76 \pm 3.26$ & $17.48 \pm 2.55^{\mathrm{a}}$ & $17.26 \pm 2.17^{\mathrm{a}}$ & 6.05 & 0.004 \\
Study $(\mathrm{n}=23)$ & $19.81 \pm 3.37$ & $13.16 \pm 2.42^{\mathrm{bc}}$ & $12.66 \pm 2.21^{\mathrm{bc}}$ & 49.75 & $<0.001$ \\
\hline${ }^{\mathrm{a}} P<0.05,{ }^{\mathrm{b}} p<0.01$, compared with value before treatment ${ }^{\mathrm{c}} p<0.01$, compared with control group &
\end{tabular}

${ }^{a} P<0.05,{ }^{b} p<0.01$, compared with value before treatment; ${ }^{c} p<0.01$, compared with control group

Table 4: Daily mean oxycontin dose (mean \pm SD, $\mathrm{mg}$ )

\begin{tabular}{|c|c|c|c|c|c|}
\hline Group & Initial dosage & $\begin{array}{l}\text { Mean medication } \\
\text { in } 4 \text { weeks }\end{array}$ & $\begin{array}{c}\text { Mean medication } \\
\text { dosage in 4th week }\end{array}$ & $\mathbf{F}$ & $P$-value \\
\hline Control $(n=23)$ & $76.24 \pm 22.06$ & $99.37 \pm 26.44^{b}$ & $108.37 \pm 29.28^{b}$ & 9.52 & $<0.001$ \\
\hline Study $(n=23)$ & $76.08 \pm 20.35$ & $89.39 \pm 21.32^{\mathrm{ac}}$ & $93.68 \pm 22.33^{\mathrm{ac}}$ & 4.25 & 0.018 \\
\hline
\end{tabular}

${ }^{a} P<0.05,{ }^{b} p<0.01$, compared with value before treatment; compared with the control group: ${ }^{c} p<0.05$

Table 5: Adverse reactions (N)

\begin{tabular}{lcccccc}
\hline Group & Constipation & $\begin{array}{c}\text { Decreased } \\
\text { appetite }\end{array}$ & Vomiting & Vertigo & Somnolence & $\begin{array}{c}\text { Urine } \\
\text { retention }\end{array}$ \\
\hline Control & 8 & 3 & 2 & 2 & 2 & 1 \\
Study & 7 & 5 & 4 & 2 & 3 & 2 \\
\hline
\end{tabular}


The use of oxycodone can cause adverse reactions such as constipation, nausea and vomiting. These adverse reactions can be exacerbated by increasing drug dosage. The mean dosage of oxycodone in the study group was increased, relative to the initial dosage, but lower than that of the control group. This was due to improvement in depression symptoms and prolongation of the effect of oxycontin by amitriptyline. Studies have shown that amitriptyline relieves neural pathological pain [17] and also strengthens the effectiveness of painrelieving drugs, and reduces usage of oxycodone. Amitriptyline improved the sleep quality of advanced tumor patients, although some patients had vertigo and somnolence after taking the drug.

Patients with severe cancer pain and depression need comprehensive treatment based on analgesia and anti-depression drugs. The use of anti-depression drugs to improve depression, and control of unwanted adverse reactions enhances the quality of life the patients.

\section{Limitations of the study}

Few participants were included in this study and we only collected the data in 4 weeks. It should be more cautious when the conclusion is applied.

\section{CONCLUSION}

A combination treatment consisting of oxycontin and amitriptyline has beneficial effects on patients with severe cancer pain and depression, and also produces lower adverse reactions. Thus, it enhances the quality of life of advanced tumor patients.

\section{DECLARATIONS}

\section{Conflict of Interest}

No conflict of interest associated with this work.

\section{Contribution of Authors}

We declare that this work was done by the author(s) named in this article and all liabilities pertaining to claims relating to the content of this article will be borne by the authors. All authors read and approved the manuscript for publication. Chen Di conceived and designed the study, Chen $\mathrm{Di}$ and Ding $\mathrm{Xu}$ collected and analysed the data, while Ding $\mathrm{Xu}$ wrote the manuscript. Chen $\mathrm{Di}$ and Ding $X u$ contributed equally to this work and should be considered as co-first authors.

\section{REFERENCES}

1. Lawlor PG, Lawlor NA, Reis-Pina $P$. The Edmonton Classification System for Cancer Pain: a tool with potential for an evolving role in cancer pain assessment and management. Expert Rev Qual Life Cancer Care 2018; 3: 47-64.

2. Reis-Pina P, Lawlor PG, Barbosa A. Cancer-related pain management and the optimal use of opioids. Acta Med Port 2015; 28: 376-81.

3. Hechler T, Wager J, Zernikow B. Chronic pain treatment in children and adolescents: less is good, more is sometimes better. BMC Pediatr 2014; 14: 262.

4. Mercadante S, Giarratano A. Pharmacological management of cancer pain in children. Crit Rev Oncol Hematol 2014; 91(1): 93-97.

5. Janjan $N$. Improving cancer pain control with NCCN guideline-based analgesic administration: a patientcentered outcome. J Natnl Compr Canc Netw 2014; 12 : 1243-1249.

6. Hamieh NM, Akel $R$, Anouti B, Traboulsi C, Makki I, Hamieh L, Tfayli A. Cancer-Related Pain: Prevalence, Severity and Management in a Tertiary Care Center in the Middle East. Asian Pac J Cancer Prev 2018; 19(3): 769-775.

7. Oldenmenger WH, Geerling Jl, Mostovaya I, Vissers KCP, de Graeff A, Reyners AKL, van der Linden YM. A systematic review of the effectiveness of patient-based educational interventions to improve cancer-related pain. Cancer Treat Rev 2018; 63: 96-103.

8. Richardson EM, Scott JL, Schüz N, Sanderson K, Schüz B. Qualitatively Comparing the Support Needs of People with Cancer Based on Their History of Anxiety/Depression. Oncol Ther 2017; 5(1): 41-51.

9. SMITH $H$ R. Depression in cancer patients: Pathogenesis, implications and treatment. Oncol Lett 2015; 9(4): 1509-1514.

10. Ostuzzi G, Matcham F, Dauchy S, Barbui C, Hotopf M. Antidepressants for the treatment of depression in people with cancer. Cochrane Database Syst Rev 2017; 6(6): 11006.

11. World Health Organization. Declaration of Helsinki. $\mathrm{Br}$ Med J 1996; 313(7070): 1448-1449.

12. Zheng YP, Lin KM, Zhao JP, et al. Comparative study of diagnostic systems: Chinese Classification of Mental Disorders-Second Edition versus DSM-III-R. Comprehens Psychiat 1994; 35(6): 441-449.

13. Ministry of Health of the People's Republic of China Chinese Ministry of Health. Guidelines for the diagnosis and treatment of cancer pain (2011edition). Chin J Crit Care Med 2012; 17(2): 153-158.

14. Yu Y, Yu SY. Study on the Assessment Index of Normative Cancer Pain Diagnosis and Treatment. Chin $J$ Pain Med 2012; 18(4): 225-230.

15. Lee KH, Kim TW, Kang JH, Kim JS, Ahn JS, Kim SY, Yun HJ, Eum YJ, Koh SA, Kim MK, et al. Efficacy and safety of controlled-release oxycodone/naloxone versus controlled-release oxycodone in Korean patients with

Trop J Pharm Res, January 2019; 18(1): 133 
cancer-related pain: a randomized controlled trial. Chin J Cancer 2017; 36(1): 74.

16. Ma H, Liu Y, Huang L, Zeng XT, Jin SH, Yue GJ, Tian X, Zhou JG. The Adverse Events of Oxycodone in CancerRelated Pain: A Systematic Review and Meta-Analysis of Randomized Controlled Trials. Med 2016; 95(15): 3341.
17. Mishra S, Bhatnagar S, Goyal G N, Rana SP, Upadhya $S P$. A comparative efficacy of amitriptyline, gabapentin, and pregabalin in neuropathic cancer pain: a prospective randomized double-blind placebo-controlled study. Am J Hosp Palliat Care 2012; 29(3): 177. 